\title{
Non-Uniformity of Water Demands in a Rural Water Supply System
}

\author{
Joanna Gwoździej-Mazur*, Kamil Świętochowski² \\ 1 Department of Technology and Systems of Environmental Engineering, Faculty of Civil and Environmental \\ Engineering, Bialystok University of Technology, ul. Wiejska 45A, 15-351 Bialystok, Poland \\ * Corresponding author's e-mail: j.mazur@pb.edu.pl
}

\begin{abstract}
The increasingly frequent use of computer simulations for the calculations concerning the water supply systems requires accounting for the demand patterns. Determining the coefficients of daily and hourly non-uniformity is indispensable for the correct designing or modernization of pipes in the water supply network. The first goal of article was to obtain the non-uniformity index for the preparation of hydraulic models in rural water systems called "N" system and "CWK" system. In this article, the authors present the results of the water consumption analysis in two rural water supply systems. The article presents the water consumption non-uniformity factors calculated over the course of a year, a month and a day. The article also included the calculated water demand curves over the course of a day, showing the variability of water demand with characteristic morning and evening water consumption peaks and changes of the consumption curve in the prospective development of the water supply network, where industrial consumers would become the main water consumers. The research material consisted of the water consumption measurements in two rural water supply networks situated in northeastern Poland, taken over the years 2010-2017. The article also shows the water demand curves in the studied rural water supply networks for every day of the week. The values of minimum and maximum hourly non-uniformity coefficients were compared to the mean value of these coefficients. The changes in the values of minimum and maximum hourly coefficients with respect to the mean value for the given hour may differ from $-89 \%$ to $+85 \%$ for hours of minimum demand. The changes in the values of minimum and maximum hourly coefficients with respect to the mean value for the given hour may differ from $-16 \%$ to $+30 \%$ for hours of maximum demand.
\end{abstract}

Keywords: rural water supply, demand patterns

\section{INTRODUCTION}

The primary task of a water supply network is to supply consumers with water in the appropriate amount, under the proper pressure and with the proper quality at any time of day or night. Ensuring the correct hydraulic conditions in the water supply network is dependent on, among other things, good estimation of the unit demand for water in the settlement unit and determination of consumer's preferences with regard to the elevated and reduced water consumption. Therefore, during the designing and modernization of water supply networks, it is required to determine the daily and hourly non-uniformity of water consumption over the course of a year, and sometimes even a multi-year period. [Sunela, Puust, 2015]
Non-uniformity of water consumption over the course of a day is characterized by two coefficients - minimum hourly non-uniformity $\mathrm{N}_{\text {hmin }}$ and maximum hourly non-uniformity $\mathrm{N}_{\text {hmax }}$ (Kępa, et al., 2013). The $\mathrm{N}_{\mathrm{dmax}}$ and $\mathrm{N}_{\text {hmax }}$ coefficients constitute the basis for dimensioning pipes (Gabryszewski, 1983). The $\mathrm{N}_{\mathrm{dmin}}$ and $\mathrm{N}_{\text {hmin }}$ coefficients are adopted based on the water consumption on the day of maximum consumption (Gabryszewski, 1983) or on the day of minimum consumption (Mielcarzewicz, 2000). Non-uniformity indices can be adopted, e.g. on the basis of the size of the settlement unit (Heidrich, 2008) or depending on the size of the unit and type of housing (Tkaczukowa, Nowakowska-Błaszczyk, 1991). More and more articles concerning the changes in water consumption are appearing in 
the literature. In rural areas, in the case of orchards, the hourly non-uniformity index accepts the values of $\mathrm{N}_{\mathrm{h}}=2.7-3.0$, and in the case of daily non-uniformity, even $\mathrm{N}_{\mathrm{d}}=13-35$ (Wichowski, 2005). In the case of individual farms, daily water consumption variability is $\mathrm{N}_{\mathrm{d}}=3.5$, and hourly variability is $\mathrm{N}_{\mathrm{h}}=2.3-8.9$ (Bergel, Kaczor, 2007). Podwójci's studies from 2010 demonstrated that in the case of multi-family residential development, the daily non-uniformity index changed from 1.06 to 1.20 , depending on the studied system. The hourly non-uniformity indices amounted to $\mathrm{N}_{\mathrm{h}}=1.7-2.22$ for a weekday, and $\mathrm{N}_{\mathrm{h}}=1.65-1.94$ for a weekend day (Podwójci, 2011). In the rural water supply systems they studied, Ogiołda and Kozaczek calculated the daily non-uniformity indices to be $\mathrm{N}_{\mathrm{d}}=1.3$ or $\mathrm{N}_{\mathrm{h}}=1.7$, and hourly nonuniformity to be $\mathrm{N}_{\mathrm{h}}=1.55$ or $\mathrm{N}_{\mathrm{h}}=1.62$ (Ogiołda, Kozaczek, 2013). Hourly non-uniformity in large cities like Kraków, within a single zone, ranges from 1.312 (Tuesday) to 1.769 (Monday). For the same zone in Kraków, daily non-uniformity over the years 2007-2012 ranged from 1.210 (Thursday) to 1.499 (Friday) (Płoskonka, Beńko, 2014). During the application of mathematical modeling for the purposes of designing the water supply network in Zator commune, the indices at the levels of $\mathrm{N}_{\mathrm{h}}=1.32$ and $\mathrm{N}_{\mathrm{d}}=1.21$ were adopted for the existing status, and for the prospective status accounting for the Economic Activity Zone (industry), $\mathrm{N}_{\mathrm{h}}=1.65$ and $\mathrm{N}_{\mathrm{d}}=1.2$ (Wierzbicki, 2015). In the case of tourist locations, the ratio of maximum daily water consumptions to mean water consumption in a month is also checked besides the daily non-uniformity determined for the day of maximum water consumption during the year (Usiudas, Filon, 2011).

Water Distribution Systems models (WDS models) performed as dynamic models - Extended-period simulations (EPS) need a demand pattern to calculate the demand changes at nodes. Consumption in a node is calculated as Eq. 1 [Letting, et al., 2017, Do, et al., 2017]:

$$
\mathrm{D}_{\mathrm{i}, \mathrm{k}}=\mathrm{m}_{\mathrm{i}, \mathrm{k}} \times \mathrm{D}_{0, \mathrm{i}}
$$

where: $D_{i, k}$ is the nodal demand,

$m_{i, k}$ is the demand multiplier for node $\mathrm{i}$, $D_{0, \mathrm{i}}^{i, \mathrm{k}}$ is the base demand for node $\mathrm{i}$.

Multiplier coefficient are non-uniformity index. The choice of the non-uniformity index calculated for hours, days or another unit of time is dependent upon the purpose of the model. WDS MODELS can be created for three different levels of demand modelling [Blokker, et al., 2008, Blokker, 2010, Li, Buchbergerm, 2004]: the first level applies to planning the work of the treatment plant, for which it is important to model the demand per day for the total supply area of a pumping station. The second level is the transport level depicting the changes on the network in time step equal to 1 hour, for example cooperation District Metered Areas with tanks and variable-speed drive (VSD) controlled pumps and third level is the water quality modelling, where a time scale on the order of minutes may be important.

The difference between the non-uniformity index values for a given settlement unit is higher for a smaller number of recipients and smaller for a larger number of recipients. The demand pattern is also flattened when it comes to the influence of such factors as large distribution area, high industrial demand, high leakage level, scarce supply (individual storage) [Trifunovic, 2006].

The goal of the paper was to determine the behavior of water demand in selected rural water supply networks. The authors wanted to learn about the non-uniformity of water demand in the rural water supply network considering the changes in water consumption over the years 2010-2017, non-uniformity of water consumption over the course of the year, the behavior of demand non-uniformity in months with the highest and lowest water consumption from the network, non-uniformity of water consumption on individual days of the week.

\section{METHODS}

The studies were conducted on two systems: "CWK" and "N". The "CWK" system is a rural water supply network with a length of approx. $26.0 \mathrm{~km}$ of mains and approx. 482 service lines. The "N" system is a rural water supply network with a length of approx. $32.9 \mathrm{~km}$ of mains and approx. 303 service lines. The research was conducted on the basis of archival data of the water company concerning the amount of water pumped into the water supply network and monitoring data of water intakes within the studied systems.

Monthly, daily and hourly non-uniformity indices were determined for both systems. The following formulas was used to determine nonuniformity indices Eq.2. [Heasted, et al., 2003 ]: 


$$
N_{t, a}=\frac{Q_{t, a}}{Q_{t m e a n}}
$$

where: $N_{t, a}-$ non-uniformity index , [-]

$Q_{t, a}^{t, a}-$ amount of water pumped into water supply network over time $t,\left[\mathrm{~m}^{3} / \mathrm{t}\right]$

$Q_{t \text { mean }}$ - mean amount of water pumped into water supply network over time t, $\left[\mathrm{m}^{3} / \mathrm{t}\right]$

$t$ - unit of time, [month, day, hour]

a - discriminant of maximum or minimum index for given unit of time $t$.

\section{RESULTS}

\section{Monthly non-uniformity of water consumption over the course of a year}

\section{"CWK" system}

The largest amount of water was pumped into the "CWK" system in 2011, and in 2016, water consumption was the lowest. The maximum water consumption was noted in March 2012 , which translates to a non-uniformity index of $\mathrm{N}_{\mathrm{m}}=2.12$. The minimum water consumption was noted in August 2016, which translates to a non-uniformity index of $\mathrm{N}_{\mathrm{m}}=0.12$. The months with the highest monthly non-uniformity index $\mathrm{N}_{\mathrm{m}}$ are June $\left(\mathrm{N}_{\mathrm{m}}=1.21\right)$ and July $\left(\mathrm{N}_{\mathrm{m}}=1.19\right)$, which is typical for the climate conditions in Poland. The lowest mean value of the monthly non-uniformity index $\mathrm{N}_{\mathrm{m}}=0.79$ occurs in November. The changes in non-uniformity index $\mathrm{N}_{\mathrm{m}}$ in individual months of the year are presented in Figure 1.

\section{"N" system}

The lowest water consumption in the "N" system was registered in the years 2010-2011. The highest water consumption was recorded in 2014, which translates to the highest nonuniformity index of $\mathrm{N}_{\mathrm{m}}=2.04$, noted in March. The minimum water consumption was noted in February 2010, which translates to a nonuniformity index of $\mathrm{N}_{\mathrm{m}}=0.45$. The months with the highest mean monthly non-uniformity index $\mathrm{N}_{\mathrm{m}}$ are June $\left(\mathrm{N}_{\mathrm{m}}=1.11\right)$, July $\left(\mathrm{N}_{\mathrm{m}}=1.12\right)$ and $\mathrm{Au}$ gust $\left(\mathrm{N}_{\mathrm{m}}=1.21\right)$, which is typical for the climate conditions in Poland. The lowest mean value of the monthly non-uniformity index is in January $\left(\mathrm{N}_{\mathrm{m}}=0.89\right)$, February $\left(\mathrm{N}_{\mathrm{m}}=0.88\right)$ and November $\left(\mathrm{N}_{\mathrm{m}}=0.88\right)$. The changes in non-uniformity index $\mathrm{N}_{\mathrm{m}}$ in individual months of the year are presented in Figure 2.

\section{Daily non-uniformity of water consumption}

\section{"CWK" system}

Figure 3 presents the changes in daily nonuniformity in the months of maximum and minimum water consumption in the "CWK" system. The minimum value of the daily nonuniformity index amounted to $\mathrm{N}_{\mathrm{d}}=0.84$ for the month of maximum consumption, and $\mathrm{N}_{\mathrm{d}}=0.65$ for the month of minimum consumption. The mean value of the daily non-uniformity index amounted to $\mathrm{N}_{\mathrm{d}}=1.24$ for the month of maximum consumption, and $\mathrm{N}_{\mathrm{d}}=0.81$ for the month of minimum consumption. The maximum value of the daily non-uniformity index amounted to $\mathrm{N}_{\mathrm{d}}=1.84$ for the month of maximum consumption, and $\mathrm{N}_{\mathrm{d}}=1.06$ for the month of minimum

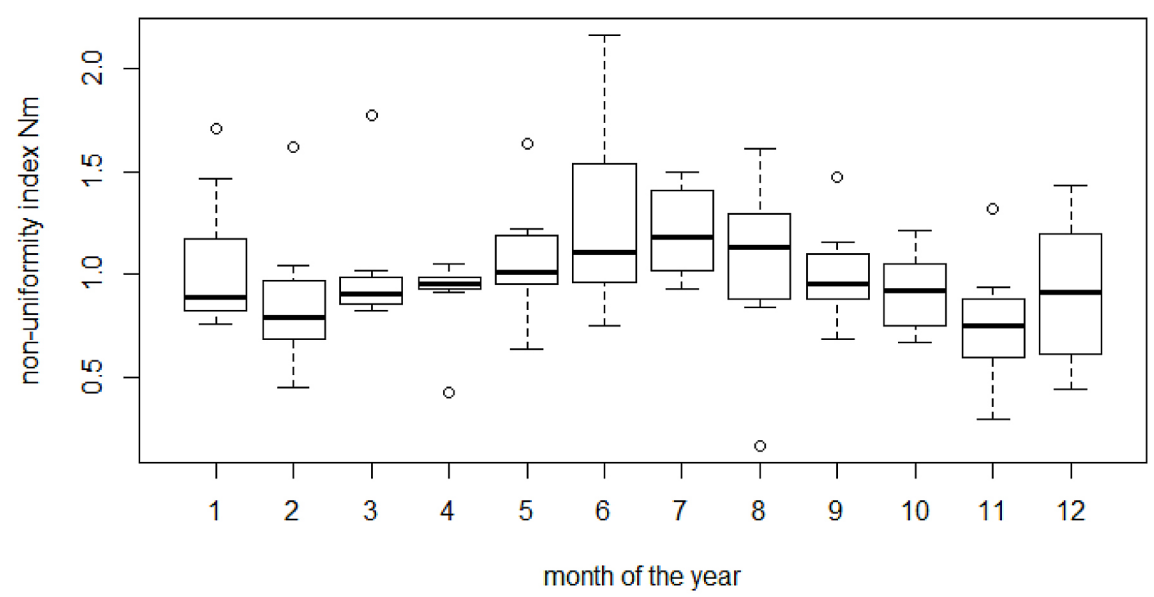

Figure 1. Non-uniformity indices of monthly water consumption in "CWK" system over the years 2010-2017 


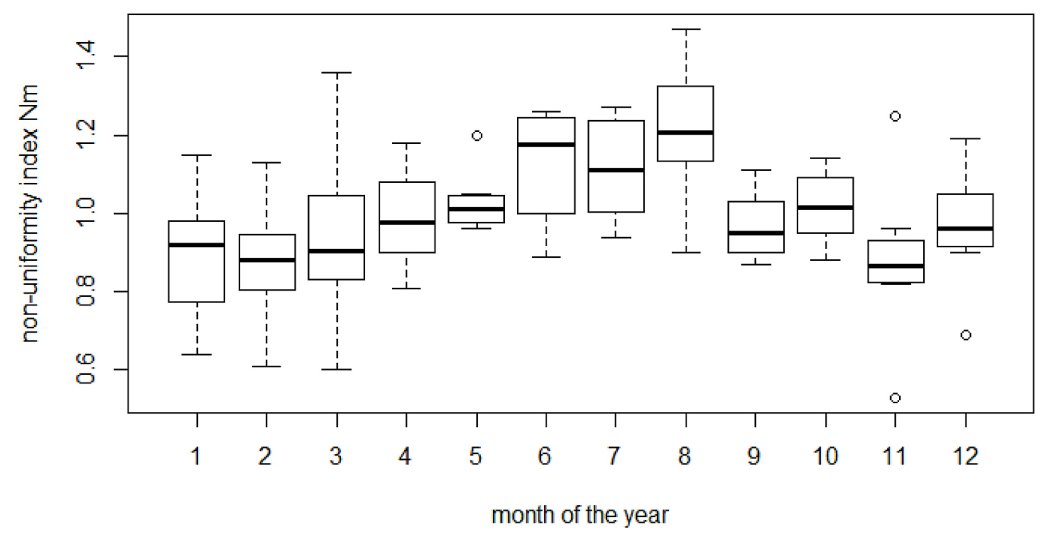

Figure 2. Non-uniformity indices of monthly water consumption in "N" system during the years 2010-2017

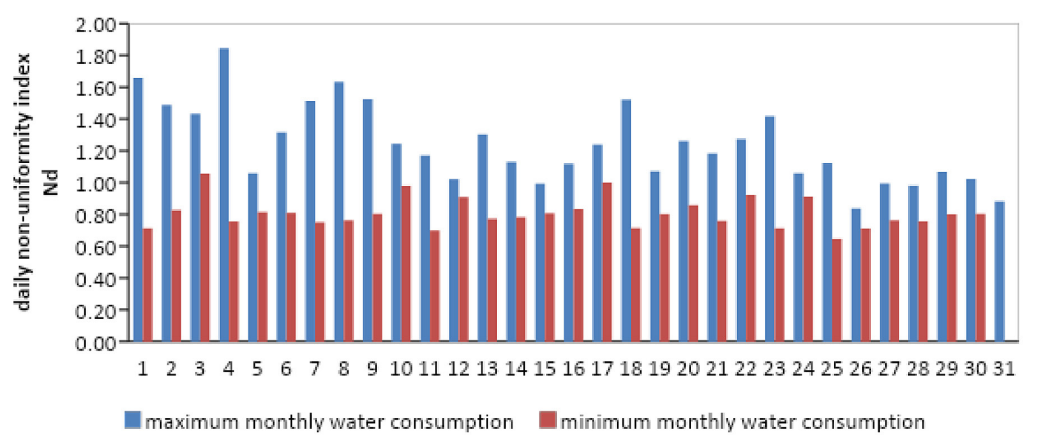

Figure 3. Changes in daily non-uniformity in the months of maximum and minimum water consumption

consumption. On the basis of the chart, periodic repeatability of the day of minimum water consumption can be observed every 7 days (Sunday). Periodic repeatability of the day with maximum water consumption is not observable.

\section{"N" system}

Figure 4 presents the changes in daily nonuniformity in the months of maximum and minimum water consumption in the "CWK" system. The minimum value of the daily nonuniformity index amounted to $\mathrm{N}_{\mathrm{d}}=0.84$ for the month of maximum consumption, and $\mathrm{N}_{\mathrm{d}}=0.79$ for the month of minimum consumption. The mean value of the daily non-uniformity index amounted to $\mathrm{N}_{\mathrm{d}}=1.20$ for the month of maximum consumption, and $\mathrm{N}_{\mathrm{d}}=0.91$ for the month of minimum consumption. The maximum value of the daily non-uniformity index amounted to $\mathrm{N}_{\mathrm{d}}=1.67$ for the month of maximum consumption, and $\mathrm{N}_{\mathrm{d}}=1.12$ for the month of minimum consumption. On the basis of the chart, no periodic (every 7 days), repeating days of maximum or minimum water consumption during the week can be observed.

\section{Hour non-uniformity of water consumption}

\section{"CWK" system}

Figure 5 presents curves of the changes of daily demand on individual days of the week based on the values of the mean hourly non-uniformity index. The changes in water consumption in the "CWK" system are characterized by two periods of elevated water consumption and two periods of reduced water consumption. Peak morning consumption occurs between 7 A.M. and 11 A.M. Peak evening consumption occurs between 6 P.M. and 10 P.M. Water consumption drops between 4 P.M. and 6 P.M. It can also be seen that water demand in the "CWK" water supply network practically disappears during the hours from 2 A.M. to 4 A.M. In the studied system, the residents' preferences on Monday and Sunday are different than on other days of the week. The Monday's water demand pattern is characterized by high water demand in the morning $\left(\mathrm{N}_{\mathrm{h}}=1.64\right)$ and lower peak water consumption in the evening $\left(\mathrm{N}_{\mathrm{h}}=1.26\right)$. The first peak of water consumption on Sunday corresponds to 2 P.M. and is characterized by $\mathrm{N}_{h}=1.83$, while the evening peak is characterized by $\mathrm{N}_{\mathrm{h}}=1.92$. 


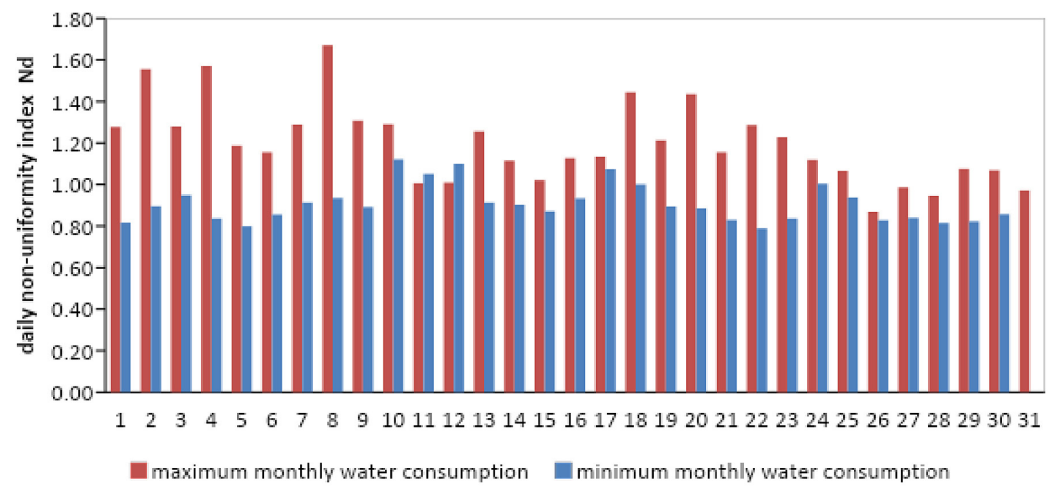

Figure 4. Changes in daily non-uniformity in the months of maximum and minimum water consumption

Table 1 presents certain values of hourly non-uniformity indices (mean, minimum and maximum value of hourly non-uniformity index) and the percentage relative to the mean value of the hourly non-uniformity index by which the maximum and minimum value of the hourly non-uniformity index changes. The values of hourly non-uniformity indices change from $-89 \%$ to $+85 \%$ of the value of the mean hourly non-uniformity index.

\section{"N" system}

Figure 5 presents curves of the changes of daily demand on individual days of the week based on values of the mean hourly non-uniformity index. The changes in water consumption in the " $\mathrm{N}$ " system are characterized by two periods of elevated water consumption and two periods of reduced water consumption. Peak morning consumption occurs between 8 A.M. and 10 A.M. Peak evening consumption occurs between 4 P.M. and 9 P.M. Water consumption drops between 11 A.M. and 3 P.M. It can also be seen that water demand in the "N" water supply network is lowest during the hours from 2 A.M. to 5 A.M. but does not disappear. In the studied system, the residents' preferences on Thursday and Sunday are different than on other days of the week. The Thursday's water demand pattern is characterized by three peaks of water consumption - the highest water demand in the morning between 8 A.M. and 9 A.M. $\left(\mathrm{N}_{\mathrm{h}}=1.39\right)$, the second peak at 4 P.M. $\left(\mathrm{N}_{\mathrm{h}}=1.54\right)$ and the third at 7 P.M. $\left(\mathrm{N}_{\mathrm{h}}=1.51\right)$. Sunday's water demand pattern is characterized by constant water consumption between 8 A.M. and 3 P.M., with a small peak at 9 A.M. $\left(\mathrm{N}_{\mathrm{h}}=1.47\right)$ and elevated water consumption between 3 P.M. and 9 P.M. with two small peaks at 4 P.M. and 6 P.M. $\left(\mathrm{N}_{\mathrm{h}}=1.61\right)$

Table 2 presents certain values of hourly non-uniformity indices (mean, minimum and maximum value of hourly non-uniformity index) and the percentage relative to the mean value of the hourly non-uniformity index by which the maximum and minimum value of the hourly non-uniformity index changes. The values of hourly non-uniformity indices change from $-20 \%$ to $+24 \%$ of the value of the mean hourly non-uniformity index.

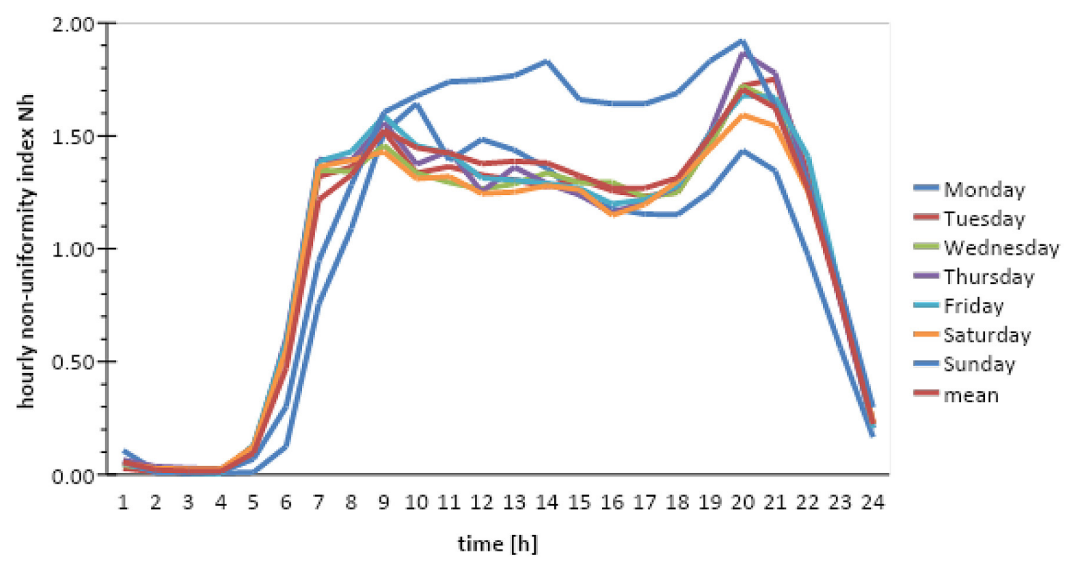

Figure 5. Daily water demand curves in "CWK" system during the week 
Table 1. Changes in hourly non-uniformity indices over the course of the week in the "CWK" system

\begin{tabular}{|c|c|c|c|c|c|}
\hline Hour & Mean & Min & Max & Delta min & Delta max \\
\hline 2 & 0.02 & 0.01 & 0.03 & $-60 \%$ & $85 \%$ \\
\hline 3 & 0.01 & 0.00 & 0.03 & $-77 \%$ & $82 \%$ \\
\hline 4 & 0.10 & 0.01 & 0.13 & $-89 \%$ & $37 \%$ \\
\hline 8 & 1.52 & 1.43 & 1.60 & $-6 \%$ & $5 \%$ \\
\hline 15 & 1.27 & 1.15 & 1.64 & $-9 \%$ & $30 \%$ \\
\hline 18 & 1.50 & 1.25 & 1.83 & $-16 \%$ & $22 \%$ \\
\hline 19 & 1.71 & 1.43 & 1.92 & $-16 \%$ & $13 \%$ \\
\hline 20 & 1.62 & 1.34 & 1.78 & $-17 \%$ & $9 \%$ \\
\hline
\end{tabular}

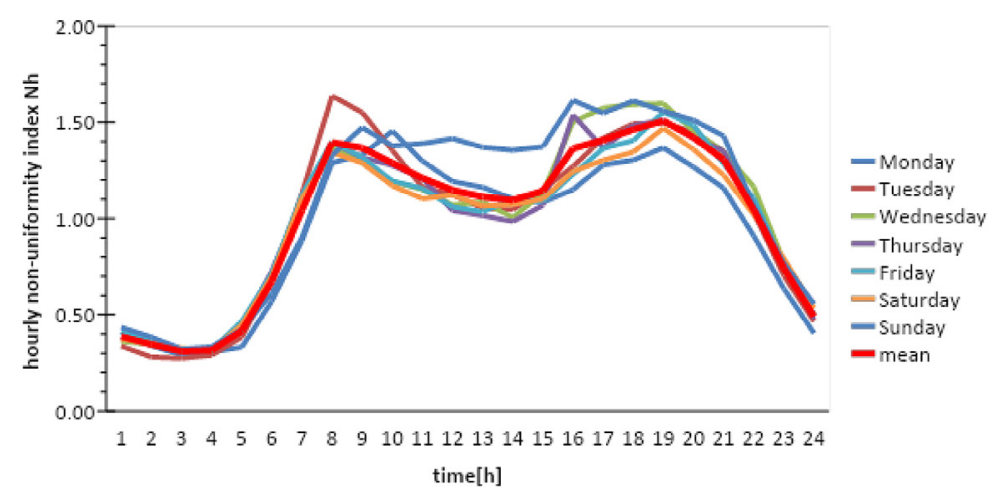

Figure 6. Daily water demand curves in "N" system during the week

\section{CONCLUSIONS}

In the studied rural water supply networks, the changes in monthly water consumption varied from 0.12 to 2.22 of the mean monthly value of water consumption. Very low values of monthly water consumption, below 0.5 , were linked to failures of the water supply network and emergency supply of the studied systems from neighboring water supply systems. In both systems, the highest consumptions were noted in August and the lowest in November. A larger range of changes in the value of the daily non-uniformity index was noted for the months of the greatest consumption $\left(\mathrm{N}_{\mathrm{d}}=\{0.84: 1.84\}\right)$ and the smallest range of changes was noted for the months with the lowest consumption $\left(\mathrm{N}_{\mathrm{d}}=\{0.65: 1.12\}\right)$. The demand patterns of hourly non-uniformities in both systems were characterized by two main water consumption peaks, in the morning and evening, as well as by very low water consumption, or even no consumption, during the night. The changes in the values of minimum and maximum hourly coefficients with respect to the mean value for a given hour differed from $-89 \%$ to $+85 \%$ for hours of minimum demand. The changes in the values of minimum and maximum hourly coefficients with respect to the mean value for a given hour differed from $-16 \%$ to $+30 \%$ for hours of maximum demand.

The values of hourly non-uniformity index in the "N" system have smaller difference than in the "CWK" system, even though the "N" system has fewer consumers. The hourly non-uniformity index did not exceed 1.65 for "N" system and 2.22 for "CWK" system. These results are comparable to the results of the other rural water supply systems found in the literature.

Table 2. Changes in hourly non-uniformity indices over the course of the week in the "N" system

\begin{tabular}{|c|c|c|c|c|c|}
\hline Hour & Mean & Min & Max & Delta min & Delta max \\
\hline 2 & 0.31 & 0.27 & 0.33 & $-12 \%$ & $5 \%$ \\
\hline 4 & 0.42 & 0.33 & 0.47 & $-20 \%$ & $12 \%$ \\
\hline 7 & 1.39 & 1.29 & 1.64 & $-8 \%$ & $17 \%$ \\
\hline 13 & 1.10 & 0.98 & 1.36 & $-10 \%$ & $24 \%$ \\
\hline 18 & 1.51 & 1.37 & 1.60 & $-9 \%$ & $6 \%$ \\
\hline
\end{tabular}


The presented material may constitute a source of data for the preparation of a computer model of water supply network operation in the studied systems. Daily water demand curves can be converted to multipliers demand pattern and used to simulate the water distribution system in the months of small and large water consumption. Non-uniformity index from this paper can help in optimizing the work of the existing pumping stations or help in the modernization of pumping sets based on the results from the computer hydraulic model.

\section{Acknowledgements}

The studies were carried out in the framework of working No. WZ/WBiIŚ/02/2019 and financed from the funds for science MNiSW.

\section{REFERENCES}

1. Bergel T., Kaczor G. 2007. Quantity and irregularity of water intake by individual rural households. INFRASTRUCTURE AND EKOLOGY OF RURAL AREAS, 1, 125-136.

2. Blokker E. J. M., Vreeburg J. H. G., Vogelaar A. J. 2008. Combining the probabilistic demand model SIMDEUM with a network model. 8th Annual Water Distribution Systems Analysis Symposium 2006. 1-11.

3. Blokker E.J.M. 2010. Stochastic water demand modelling for a better understanding of hydraulics in water distribution networks. Ph.D. Thesis, Delft University of Technology, Delft.

4. Do N.C., Simpson A.R., Deuerlein J., Piller O. 2017. Demand Estimation In Water Distribution Systems: Solving Underdetermined Problems Using Genetic Algorithms. Procedia Engineering, 186, 193-201.

5. Gabryszewski T. 1983. Water Distribution Systems. Publishing House Arkady, Warsaw.

6. Haestad M., Walski T.M., Chase D.V., D.A. Savic, Grayman W., Beckwith S., Koelle E. 2003. Adavanced Water Distribution Modeling and Managment. Haestad Press Waterbury.

7. Heidrich Z. 2008. Water Distribution Systems. Publishing House WSiP, Warsaw.
8. Kępa U., Stępniak L., Stańczyk-Mazan E. 2013. Analysis of Water Consumption and Demand Variation in Kawie Góry Supply Area in the City of Częstochowa. Annual Set The Environment Protection, 15, 2546-2562.

9. Letting L.K., Hamam Y., Abu-Mahfouz A.M. 2017. Estimation of Water Demand in Water Distribution Systems Using Particle Swarm Optimization. Water, 9, 593.

10. Li Z., Buchbergerm S. 2004. Effect of Time Scale on PRP Random Flows in Pipe Network. 1-10. 10.1061/40737(2004)461.

11. Mielcarzewicz E. 2000. Calculation of water supply systems. Publishing House Arkady, Warsaw.

12. Ogiołda E., Kozaczek M. 2013. Characteristics of water consumption in water supply systems "Wilków" and "Borek" in Głogów commune. Civil and Environmental Engineering Reports, 152(32), 69-77.

13. Płoskonka R., Beńko P. 2014. Daily changes of water demand in the single water system zone in Krakow. TECHNICAL TRANSACTIONS ENVIRONMENT ENGINEERING, 1-Ś, 35-43.

14. Podwójci P. 2011. Inequality of water consumption and distribution in apartment house building. Ecological Engineering, 26, 281-289.

15. Sunela M., Puust R.. 2015. Modeling water supply system control system algorithms. Procedia Engineering, 119, 734-743.

16. Tkaczukowa B., Nowakowska-Błaszczyk A. 1991. Guidelines for programming the water demand and the amount of sewage in municipal settlement units. Publishing Agency of the Institute of Spatial and Communal Economy, Warsaw.

17. Trifunovic N. 2006. Introduction to Urban Water Distribution. Taylor \& Francis Ltd, London.

18. Usiudas D., Filon A. 2011. Analysis of Variability of Water Consumption in the Baltic Coast Resort. Annual Set The Environment Protection, 13, 903-920.

19. Wichowski P. 2005. Forecasting of water requirements in fruit farms. Scientific Review Engineering and Environmental Sciences, 32, 81-89.

20. Wierzbicki R. 2015. Improvements designing of water supply systems on the example of zator municipality water supply system. JCEEA, 32(62), 511-522. 